\title{
BMJ Open Beliefs underlying pain-related fear and how they evolve: a qualitative investigation in people with chronic back pain and high pain-related fear
}

\author{
Samantha Bunzli, ${ }^{1}$ Anne Smith, ${ }^{1}$ Robert Schütze, ${ }^{2}$ Peter O'Sullivan ${ }^{1}$
}

To cite: Bunzli S, Smith A, Schütze $\mathrm{R}$, et al. Beliefs underlying pain-related fear and how they evolve: a qualitative investigation in people with chronic back pain and high pain-related fear. BMJ Open 2015;5:e008847. doi:10.1136/bmjopen-2015008847

- Prepublication history and additional material is available. To view please visit the journal (http://dx.doi.org/ 10.1136/bmjopen-2015008847).

Received 21 May 2015 Revised 4 September 2015 Accepted 15 September 2015

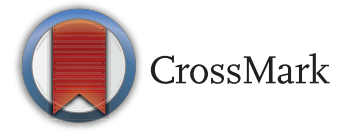

${ }^{1}$ School of Physiotherapy and Exercise Science, Curtin University, Perth, Western Australia, Australia ${ }^{2}$ School of Psychology and Speech Pathology, Curtin University, Perth, Western Australia, Australia

Correspondence to Samantha Bunzli; samantha.bunzli@postgrad. curtin.edu.au

\section{ABSTRACT}

Objectives: The fear-avoidance model describes how the belief that pain is a sign of damage leads to painrelated fear and avoidance. But other beliefs may also trigger the fear and avoidance responses described by the model. Experts have called for the next generation of fear avoidance research to explore what beliefs underlie pain-related fear and how they evolve. We have previously described damage beliefs and suffering/ functional loss beliefs underlying high pain-related fear in a sample of individuals with chronic back pain. The aim of this study is to identify common and differential factors associated with the beliefs in this sample.

Design: A qualitative study employing semistructured interviews.

Setting: Musculoskeletal clinics in Western Australia.

Participants: 36 individuals with chronic back pain and high scores on the Tampa Scale (mean 47/68).

Results: The overarching theme was a pain experience that did not make sense to the participants. The experience of pain as unpredictable, uncontrollable and intense made it threatening. Attempting to make sense of the threatening pain, participants with damage beliefs drew on past personal experiences of pain, societal beliefs, and sought diagnostic certainty. Met with diagnostic uncertainty, or diagnoses of an underlying pathology that could not be fixed, they were left fearful of damage and confused about how to 'fix' it. Participants with suffering/functional loss beliefs drew on past personal experiences of pain and sought help from healthcare professionals to control their pain. Failed treatments and the repeated failure to achieve functional goals left them unable to make 'sensible' decisions of what to do about their pain.

Conclusions: The findings raise the suggestion that sense-making processes may be implicated in the fearavoidance model. Future research is needed to explore whether fear reduction may be enhanced by considering beliefs underlying fear and providing targeted intervention to help individuals make sense of their pain.

\section{INTRODUCTION}

Pain-related fear is one of the strongest modifiable predictors of disability in low

\section{Strengths and limitations of this study}

- Interviews with 36 individuals with high painrelated fear (mean 47/68 on the Tampa Scale) provide insight into the beliefs underlying fear and how they evolve.

- Findings from the 'lived experience' of people with high pain-related fear provide an evidencebased platform for future iterations of the fearavoidance model.

- This study employed purposive sampling to capture a range of experiences of pain-related fear; it is unknown how representative this finding is to the greater population of individuals with chronic low back pain and high pain-related fear.

back pain (LBP). ${ }^{1}{ }^{2}$ In line with the theory that cognitive factors precede emotional reactions, ${ }^{3}$ the fear-avoidance model $(\mathrm{FAM})^{4}$ proposes that individuals with LBP who believe their pain is 'a sign of serious injury or pathology, ${ }^{5}$ may become fearful and avoidant of physical activity that they presume worsens their problem. The avoidance of activity prevents opportunities to challenge negative expectations and may exacerbate pain and disability.

Since its publication, research has largely supported the relationships proposed by the FAM. ${ }^{6-9}$ However experts have identified limitations in the current FAM and made suggestions for how research may inform the next generation of FAM. ${ }^{510} 11$ One such suggestion is that while the FAM assumes that all individuals with LBP interpret pain as a sign of damage, it is possible that other beliefs trigger the fear and avoidance responses described by the FAM. ${ }^{5}$

Currently, interventions based on the FAM target the belief that pain is a sign of serious injury or pathology. ${ }^{12}$ These interventions have successfully reduced fear and disability 
in some individuals with LBP and high pain-related fear, but a significant proportion fail to respond to treatment. ${ }^{13-15}$ Understanding what beliefs underlie painrelated fear and how they evolve may assist in directing fear reduction interventions that target specific beliefs.

Several qualitative studies have investigated the beliefs of people with LBP. Stenberg et $a l^{16}$ explored pain beliefs in relation to physical activity (including exercise and work) in participants with acute and chronic neck pain and LBP. They identified 'fear of hurting the fragile body' as the salient theme and found that earlier experiences of pain and activity undermined fear of damage. Similarly, Darlow et $a l^{17}$ explored the factors involved in the development of LBP beliefs in participants with acute and chronic LBP and found strong social influences, particularly that of healthcare professionals (HCPs), on the genesis of positive and negative LBP beliefs. While providing insight into potential factors contributing to LBP beliefs, these studies included participants with acute and chronic pain whose beliefs have been shown to differ ${ }^{18}$ and the studies did not select for individuals with high pain-related fear.

In a previous publication we reported on the beliefs of individuals with chronic non-specific LBP (CNSLBP) scoring highly for pain-related fear on the Tampa Scale of Kinesiophobia (TSK). In a qualitative study of 36 people, Bunzli $e t a l^{19}$ found that some individuals believed painful activity had damaging consequences for the structural integrity of the spine (damage beliefs); while others believed painful activity would increase suffering and/or lead to subsequent functional loss (suffering/functional loss beliefs); and some held both beliefs. In the report we stopped short of investigating the factors that contribute to these beliefs and to date our understanding of why individuals with CNSLBP and high pain-related fear associated LBP with damage, suffering and/or functional loss remains limited.

To build an evidence-base for future iterations of the FAM that may direct targeted fear reduction interventions, this study aimed to identify common and differential factors associated with beliefs underlying fear in individuals with CNSLBP and high scores on the TSK.

\section{METHODS}

All participants read the study explanatory sheet and gave written informed consent prior to participation.

An Interpretive Description framework ${ }^{20}$ was chosen for this study as it adheres to the systematic reasoning of health professions with the objective of informing clinical practice. This paradigm acknowledges the theoretical and practical knowledge the health researchers brings to the study, laying visible their assumptions and beliefs that influence the design and findings. In this study, the Interpretive Description framework enabled the researchers to draw on their clinical and theoretical knowledge of biopsychosocial processes and the FAM to design a study that could explore the factors contributing to damage beliefs and suffering/functional loss beliefs among individuals with CNSLBP with implications for clinical practice.

The authors of this paper are clinical and research physiotherapists and a clinical psychologist with interests in the clinical application of biopsychosocial models of chronic pain. This study is part of the first authors' (SB) doctoral studies. SB is a physiotherapist with 10 years of clinical experience.

This study followed the consolidated criteria for reporting qualitative research (COREQ) guidelines ${ }^{21}$ (see online supplementary material).

\section{Sample}

This study involves the same sample as has been previously described in Bunzli et al. ${ }^{19}$ The sample is described in detail below.

Participants seeking care from a range of musculoskeletal practitioners (general practitioners, physiotherapists, chiropractors and pain clinics) in Perth, Western Australia were recruited through purposive sampling.

Adults aged 18-65 years with CNSLBP of $\geq 6$-month duration and pain intensity $\geq 3 / 10$ on the visual analogue scale were eligible for inclusion. Individuals who presented with specific causes of LBP including red flags, radicular pain with nerve compression and spondylolisthesis and pregnancy-related LBP were excluded. Individuals with high fear were eligible for inclusion. High pain-related fear was identified by scores $\geq 40$ on the 17-item TSK (R Miller, S Kori, D Todd. The Tampa Scale. Unpublished, 1991)as consistent with previous literature. $^{22}$

\section{Recruitment}

Participating clinics identified individuals meeting the inclusion criteria between May 2012 and May 2013. Individuals were provided with the study information sheet and invited to contact the researchers if they were interested in participating in a study being conducted by a doctoral student at the school of physiotherapy investigating pain-related beliefs and emotions of people with CNSLBP. Purposive sampling involved regular contact between the researchers and participating clinics throughout the study period. In this way sampling was adjusted in response to data emerging from the simultaneous processes of recruitment, interviews and data analysis. For example, after approximately one-third of the interviews had been conducted and analysed, the researchers decided that more male participants were required to ensure a more balanced representation of gender. At this time, clinicians were asked to only hand the invitations to males who fit the inclusion criteria until the gender representation had been addressed. Recruitment continued in this way until saturation was reached. Saturation was reached when the authors considered that the inclusion of further participants would not influence the main themes identified in this study. ${ }^{23}$ Purposive sampling was performed in order to capture a 
wide range of experiences of pain-related fear. As such it is unknown how representative the final sample is of the larger population with CNSLBP and high pain-related fear.

All participants who contacted the researchers were included. This paper describes the experiences of 36 individuals who gave written informed consent and participated in the study. The participants were $69 \%$ female with an average of 42 years of age. The mean duration of CNSLBP was 7 years and the mean score on the TSK was $47 / 68$. Participant characteristics are presented in table 1 .

\section{Data collection}

Semistructured interviews were conducted by SB, a female physiotherapist and $\mathrm{PhD}$ candidate with experience in conducting qualitative interviews. Prior to the interviews, SB was not working as a clinical physiotherapist and was not known to the participants and therefore had no pre-existing relationship with them. Participation involved a single one-to-one interview conducted in the participants' homes or a private university office. Phone interviews were conducted with two participants living in remote locations. An interview schedule guide is outlined in table 2. The content of the interviews was informed by the findings from a review of the qualitative literature exploring the lived experience of CNSLBP. ${ }^{24}$ For example, it has been suggested that fear avoidance beliefs may be influenced by advice from HCPs to avoid certain movements to 'protect' the spine, ${ }^{17}$ therefore the questions: 'What health professionals have you seen for your back pain? What have they told you about your back pain?' were included in the interview schedule.

Early interviews were guided by opening questioning. Later interviews involved both opening questioning and more refined questioning as a result of concurrent data analysis of previous interviews. Participants were able to give opinions freely during the interviews. All interviews

\begin{tabular}{|c|c|c|c|c|c|c|}
\hline Code & Sex & Age & Marital status & Occupation & TSK score & Duration LBP (years) \\
\hline 010 & Male & 39 & Married & Disability pension & 42 & 13 \\
\hline 011 & Female & 39 & Married & Administration & 65 & 0.5 \\
\hline 012 & Female & 33 & Single & Administration & 53 & 12 \\
\hline 013 & Female & 51 & Single & Nurse & 56 & 2 \\
\hline 014 & Female & 39 & Married & Teacher & 42 & 4 \\
\hline 015 & Female & 25 & De facto & Nurse & 46 & 0.5 \\
\hline 016 & Female & 41 & Married & Construction & 48 & 0.75 \\
\hline 017 & Male & 42 & Married & Teacher & 50 & 2 \\
\hline 018 & Male & 54 & Single & Unemployed & 46 & 6 \\
\hline 019 & Male & 33 & Single & Mechanic & 45 & 8 \\
\hline 020 & Female & 33 & De facto & Police officer & 46 & 0.5 \\
\hline 022 & Female & 60 & Married & Market research & 51 & 13 \\
\hline 024 & Female & 61 & Married & Task manager & 45 & 10 \\
\hline 025 & Female & 61 & Married & Administration & 42 & 0.5 \\
\hline 026 & Male & 49 & Single & Disability pension & 48 & 20 \\
\hline 027 & Female & 23 & Single & Physiotherapy student & 42 & 10 \\
\hline 028 & Male & 19 & Single & Student & 47 & 2 \\
\hline 029 & Female & 53 & Single & Carer & 46 & 2 \\
\hline 030 & Female & 58 & Single & Unemployed & 46 & 19 \\
\hline 031 & Female & 27 & Single & Engineer & 42 & 0.75 \\
\hline 032 & Female & 46 & Married & Caterer & 47 & 0.75 \\
\hline 033 & Male & 43 & Single & Unemployed & 40 & 14 \\
\hline 036 & Female & 41 & Married & Horse trainer & 41 & 7 \\
\hline 037 & Female & 43 & Married & Unemployed & 46 & 1 \\
\hline 038 & Female & 45 & Married & Unemployed & 40 & 12 \\
\hline 039 & Female & 38 & Divorced & Unemployed & 46 & 4 \\
\hline 042 & Female & 45 & Divorced & Unemployed & 55 & 27 \\
\hline 043 & Female & 47 & Single & Unemployed & 48 & 2 \\
\hline 044 & Female & 42 & Married & Teacher & 46 & 11 \\
\hline 045 & Male & 29 & Single & Unemployed & 41 & 2 \\
\hline 046 & Male & 64 & Divorced & Small business & 53 & 8 \\
\hline 047 & Female & 41 & Married & Sick leave, administration & 53 & 1 \\
\hline 048 & Female & 39 & Separated & Unemployed & 42 & 29 \\
\hline 049 & Female & 37 & Married & Administration & 40 & 4 \\
\hline 050 & Male & 38 & Separated & Sick leave, electrician & 46 & 6 \\
\hline 052 & Male & 30 & Single & Teacher & 44 & 6 \\
\hline
\end{tabular}


Table 2 Interview schedule guide

Research question Examples of open questioning

What factors are associated with beliefs underlying fear?

You have said that you worry about the consequences of low back pain-Can you please give me an example of this? Why were you worried? What did you do? Why did you do this? What would you do if you were in a similar situation again? Why would you do this?

Examples of refined questioning

Which healthcare professionals have you seen for your back pain? What have they told you about your back pain?

Can you tell me about any investigations for example, scans you have had on your back? Where/who else do you turn to for advice on your back pain? Why?

Have you been around other people who have had back pain? How did they cope with their pain?

Can you tell me about any previous experiences of back pain you may have had?

were flexible to explore any new themes that arose. The interviews lasted between $45 \mathrm{~min}$ and $2 \mathrm{~h}$.

\section{Analysis and consideration of trustworthiness}

Interviews were audio recorded and transcribed verbatim by SB immediately following the interview.

This study was designed to answer two separate research questions. In our previous paper we answered the first research question and described the beliefs underlying high scores on the TSK. We found that 14 individuals scoring highly on the TSK clearly endorsed only damage beliefs, whereas 17 individuals clearly endorsed only suffering/functional loss beliefs, and 5 individuals clearly endorsed both beliefs. ${ }^{19}$ In this paper we answer the second research question and explore the common and differential factors associated with beliefs underlying fear in this sample.

Data analysis was based on an inductive analytic approach described by Thorne $e t a l^{23}$ and involved five steps: (1) open coding, (2) intrasubject analysis: salient coding, (3) intersubject analysis: search for patterns between participants, (4) identification of emerging themes and (5) interpretive description of findings. Data analysis occurred concurrently with data collection. Steps were repeated several times to explore new directions as they arose. SB led the data analysis through steps 1-5 with input from coauthors at all stages. The transcripts were read by at least two authors. Group discussion of each transcript was conducted to familiarise all authors with the content.

In step 1, SB conducted open coding on all transcripts. A random sample of eight transcripts was selected for independent analysis by the coauthors. Comparison of coding performed by SB and the coauthors on each of the eight transcripts was done through group discussion. In this way any dissent between the interpretations made by $\mathrm{SB}$ and the relevant coauthor could be handled by reaching consensus among the remaining two coauthors who acted as independent arbiters. The authors were in agreement that the extracts and codes identified were consistent between SB and the coauthors. No new concepts were identified by the coauthors so no further cross-coding was performed. This is consistent with previous qualitative studies in this field where a single author coded all data, with corroboration by coauthors. ${ }^{17} 25-27$

Codes were derived from the raw data rather than being determined a priori. Coding was guided by the question: 'How is this relevant to this individuals' painrelated fear?'. A list of codes relevant to the participants' fear was devised. This 'code-book' was added to and refined during the analysis of subsequent interviews, in an on-going process of constant comparative analysis throughout the data analysis. ${ }^{28}$ The refined code-book had a tree-like structure that described all the raw data, with no new codes emerging from the analysis of subsequent interviews. The refined code-book was reapplied to all transcripts by SB.

In step 2, the codes considered to be most relevant and important to each individuals' experience of painrelated fear were identified as salient codes. SB identified salient codes for all transcripts and the coauthors identified salient codes on a random sample of eight transcripts. The identification of salient codes by SB and the coauthors was consistent. The coauthors reviewed and agreed on the full list of salient codes in group discussion.

In step 3, a data-sorting programme (purpose-designed by SB during her doctoral studies) grouped the extracts by code. Grouped extracts were checked by two authors to confirm that recurring codes described common aspects of participants' experiences.

In step 4, patterns of salient codes between participants were identified as emerging themes. Grouped extracts were analysed by SB to develop understanding and construct a description of the emerging theme. Emerging themes were challenged by: (1) the reanalysis of transcripts that did not fit the pattern to check that they were correctly coded, (2) group discussion among the authors to consider alternative perspectives and insights, (3) specific questioning during interviews with subsequent participants and (4) theoretical sampling in which cases of ambiguity and negative cases were specifically sought. ${ }^{28}$ 
In step 5, through group discussion among all authors, the authors interpreted the meaning of the findings by considering: (1) How may this finding influence the current clinical management of people with CNSLBP and high pain-related fear? (2) How might this finding inform future iterations of the FAM?

Data collection and data analysis continued until the research questions could be answered in a way that would yield useful knowledge for clinical practice and the authors considered that the inclusion of further participants would not alter the main themes identified. ${ }^{23}$

The grouping of salient codes into themes is presented in table 3.

\section{RESULTS}

The overarching theme was a LBP experience that did not make sense. For all participants, the experience of LBP as unpredictable, uncontrollable and/or intense made it threatening to them (theme 1). In an attempt to make sense of the threatening pain:

Participants with damage beliefs described drawing on past personal experiences of LBP (theme 2), societal beliefs (theme 3) and sought diagnostic certainty from HCPs. Met with diagnostic uncertainty, or diagnoses of an underlying pathology that could not be fixed (theme 4 ), these participants were left fearful of damage and confused about how to 'fix' it.

Participants with suffering/functional loss beliefs described drawing on past personal experiences of LBP (theme 2), and sought help from HCPs to control their pain. The repeated experience of 'failed' treatment and the failure to achieve functional goals (theme 5) left them unable to make 'sensible' decisions of what to do about their pain. Themes are described in detail below, with supporting quotes labelled by participant code and the line numbers corresponding to where the quotes appeared in the interview transcripts.
THEME 1: THE PREDICTABILITY, CONTROLLABILITY AND INTENSITY OF PAIN

Common to the accounts of all participants was the experience of LBP as intensely painful, unpredictable and/or difficult to control.

The intensity of LBP made it something scary, to be feared. Participants with damage beliefs described intense pain as an evolutionary warning signal that they should stop what they were doing to avoid damaging or (re)injuring their spine, while participants with suffering/functional loss beliefs described their distress associated with suffering intense pain:

When my back was completely bad, 10/10 pain, I got scared then, thinking what is going to happen am I going to be in a wheelchair and yeah when it gets that bad and I can't walk then that is when I do get really scared. (044, line 233)

You just don't want to live with that sort of pain...everything just stops you are just so consumed with that pain level. I am writing, I am really distressed and can't cope. It is just not good and so I avoid it. (029, line 350)

Most participants experienced their LBP as unpredictable. They described difficulties predicting what would trigger their pain, how long it would last and how well they would be able to control it. Pain that was unpredictable and uncontrollable was difficult to make sense of:

There is no set pattern when it is going to happen. And I can do things today that won't trigger it, tomorrow I do exactly the same things and it will trigger it. So nothing causes it and I can't control it. That is what is so frustrating and scary. (032, line 124)

Because it is unpredictable, it is out of your control...you don't know what you are doing to exacerbate it, you are

Table 3 Identification of themes from inductive coding

\begin{tabular}{|c|c|c|}
\hline Overarching theme & Themes & Salient codes \\
\hline \multirow[t]{15}{*}{ Inability to make sense of pain } & Damage beliefs underlying fear & Damage beliefs \\
\hline & Suffering/functional loss beliefs underlying fear & Suffering/functional loss beliefs \\
\hline & LBP threat & Pain predictability \\
\hline & & Pain controllability \\
\hline & & Pain intensity \\
\hline & Negative past experience of pain & Negative past experience of pain \\
\hline & Societal back beliefs & Societal beliefs \\
\hline & & Family beliefs \\
\hline & Process of seeking diagnostic certainty & Diagnostic uncertainty \\
\hline & & Negative information $\mathrm{HCP}$ \\
\hline & & Conflicting information \\
\hline & & Scans \\
\hline & Repeated experience of failure to control pain & Failed treatment \\
\hline & & Repeated goal failures \\
\hline & & Persistence behaviour \\
\hline
\end{tabular}


just kind of moving so you have no control and that is the scary thing. (013, line 767)

In a few divergent cases, LBP was described as highly predictable. For example, participant 032 knew what movements/activities would flare up her pain. For her, the uncontrollability rather than unpredictability of pain appeared to be associated with her pain-related fear:

If I bend, I know I will irritate my back...if it is going to irritate me for half an hour when I could achieve half an hour painfree, why would I do that? (032, line 293)

\section{THEME 2: NEGATIVE PAST PERSONAL EXPERIENCES OF PAIN}

In an attempt to try and make sense of the threatening pain experience, participants drew on their previous personal experiences of LBP. While the experience of, and recovery from, mildly debilitating LBP in the past may function to reduce fear, the previous experience of severe, debilitating LBP appeared to reinforce beliefs about the on-going weakness of the spine that is vulnerable to re-injury, and influence negative expectations of suffering/functional loss associated with pain:

I think that is where my hesitation and anxiousness comes from...no no I do not want to blow another disc... so I am just super cautious. (012, line 697)

If you (feel pain) you panic because you don't know if the pain is going to go away. You don't know if you have gone backwards...I don't want to go back to the original pain. (032, line 311)

\section{THEME 3: THE INFLUENCE OF SOCIETAL BACK BELIEFS}

Participants with damage beliefs described drawing on societal beliefs and attitudes to make sense of their pain. However the salience of damage beliefs appeared to be high among the family members, friends and colleagues that they turned to as sources of information. This reinforced their 'fear of damage' and their uncertainty about how to address it:

I guess we all have that fear of the spine...there is something about the back, that fear of my god I don't want to do something to my spine, because if I hurt my spine I am not going to be able to walk, I am not going to be able to mobilise and what if I am an invalid and I can't do anything. (013, line 11)

You grow up hearing horror stories about back surgeries and how it makes things ten times worse. (012, line 26)

\section{THEME 4: PROCESS OF SEEKING DIAGNOSTIC CERTAINTY}

Participants with damage beliefs described undiagnosed pain as 'petrifying'. For these participants receiving a diagnosis from a HCP was important in order to understand what was causing their pain and how they could 'fix' it. However many participants who consulted a HCP did not receive a diagnosis and the lack of explanation left them confused:

It could be my discs but they say not, so I am very confused and that is a big deal for me, that I don't know what it is. (038, line 190)

When you look at everything that says there is nothing to show, how can you treat it? How can you treat it when tests come back negative? (025, line 427)

Other participants did receive a diagnosis of an underlying pathology from their HCP. A poor understanding of the diagnostic jargon used by HCPs meant some participants interpreted the diagnostic 'label' they had been given as a serious underlying pathology. For example, when asked to describe how they interpreted their diagnosis of 'degeneration' these participants described a process of deterioration in the integrity of the spine:

The way I understood what they say about my back, degeneration was something about breaking down. (049, line 57)

They told me that I had degeneration...so it is a slow progressive issue that will only get worse over time. (050, line 160)

The 'diagnosis' of an underlying pathology led to confusion when participants realised that there was no option to 'fix' the underlying pathology. This participant who was told that his pain was caused by 'degeneration' and that he was not a candidate for surgery, said:

The injury is bone on bone. You know they can do hip replacements and all that sort of thing, why can't they do anything for your spine? (018, line 284)

Similarly, this participant who was told her LBP was due to 'ligament issues' said:

Why is it that you hear stories about people with cruciate ligament issues and they are back playing footie in 6 months? Like a clear path-clear diagnosis, clear treatment option with a high success rate and resolution of the problem. What makes this joint different from the other joints? Why does that treatment path not exist for this joint? (036, line 299)

\section{THEME 5: REPEATED EXPERIENCE OF FAILURE TO CONTROL PAIN}

Participants with suffering/functional loss beliefs described consulting HCPs in search of strategies to gain control over their pain. However the strategies they were provided with had limited effectiveness: 
He says we need to get you back in to the gym and moving and I say yeah but on Friday I tried to exercise again and I was down and out the weekend. I don't have time to be down and out. I have to work. (049, line 236)

When they failed to meet their expected treatment outcomes despite adhering closely to the recommendations of their HCPs, this reinforced the unpredictability and uncontrollability of their pain and left them uncertain of what to do next:

That's the point that I couldn't understand like I am doing everything they want me to do. I am doing physio, I am moving and trying all this and the pain isn't dying. This is crazy. (010, line 128)

I've been blown off by everyone and stuff I had sought for myself hadn't really worked. I don't know what to do. (016, line 455)

With a lack of strategies to control pain, participants with suffering/functional loss beliefs described being 'stuck' trying to make sensible functional choices when all options had undesirable outcomes. This participant provided an example of how she 'weighed up' whether walking home with heavy groceries would cause her more pain than sitting in the car:

Its always a weigh-up: how many groceries am I getting, therefore can I walk back with the shopping? Versus sitting in the car to drive. (016, line 635)

Some participants decided to ignore pain and persist with functional tasks despite pain. However persistence inevitably resulted in flare-ups of pain that forced them to abandon the task:

So you have a cramp but it is 5 o'clock and there are a billion things to get done...I just get on with it. But within an hour I have to get heat on it because it starts to ache, deep in the bone it...Every night I sit on the couch and put heat packs on it. (049, line 590)

The repeated experience of failing to achieve functional goals due to exacerbations in pain reinforced the participants' inability to make sense of their pain:

I don't know what to do, it doesn't make sense to me. (024, line 20).

\section{DISCUSSION}

We have previously documented two predominant beliefs in this sample of individuals with CNSLBP and high pain-related fear. ${ }^{19}$ The aim of this study was to explore factors associated with these underlying beliefs. The overarching theme across all participants was the experience of a threatening pain that they could not make sense of. Participants described attempts to make sense of pain that varied depending on their beliefs underlying fear.

\section{Pain that does not make sense}

That sense-making processes may play a role in painrelated fear is a novel suggestion that is in contrast to the 'phobic' processes described by the FAM. An inability to make sense of CNSLBP symptoms has been documented in other qualitative investigations of the CNSLBP experience. Studies have described 'the riddle of the puzzling pain' ${ }^{29}$ and the 'bewildering situation' of repeatedly unmet expectations of CNSLBP treatment. ${ }^{30}$ A metasynthesis of qualitative studies described how an inability to make sense of pain placed 'lives on hold', suspending biographical timelines in people with CNSLBP. ${ }^{24}$ There is some evidence that individuals with chronic widespread pain and chronic musculoskeletal pain who cannot make sense of their symptoms are more likely to catastrophize about them. ${ }^{31}$

\section{Predictability, controllability and intensity of pain}

Predictability, controllability and stimulus intensity have been described as common to the pathways to, and maintenance of, all specific fears. ${ }^{32}$ However despite being central to the experiences of the participants in this study, the current FAM does not ascribe a role to the nature of the pain experience in pain-related fear. Emerging evidence from experimental studies in healthy participants also suggests that predictability, controllability and pain intensity may influence pain-related fear. An experimental study involving healthy participants found that the absence of safety cues makes unpredictable pain more threatening than predictable pain, resulting in increased pain-related fear. ${ }^{33}$ Another experimental study in healthy participants found that having control over pain and then losing it may result in more pain-related fear than never having had control, through heightened hypervigilance. ${ }^{34}$ A recent study involving participants with chronic pain found that in moments of more intense pain, fearful thinking about pain increased. ${ }^{35}$ These findings suggest that rather than being a static response to a stable belief, ${ }^{5}$ pain-related fear may be dynamic and responsive to changes in the pain experience.

\section{Attempts to make sense of the threatening pain experience}

Expectations from past personal experiences of pain, cultural beliefs about LBP in the general population, treatment expectations and goal context were all found to influence underlying beliefs. Considering these influences in future iterations of the FAM may be warranted. For instance, the high prevalence of pathoanatomical beliefs about LBP in society suggests that these may be 'normative' rather than being 'exceptional or irrational' as is currently inferred by the FAM..$^{5}$ A population-based cross-sectional study of people living in New Zealand found that of the 602 respondents, $89 \%$ believed their back was easy to injure and $89 \%$ believed if they ignored back pain, they may cause damage to their back. $57 \%$ of respondents believed that back pain meant they had 
injured their back and $64 \%$ believed that a 'twinge' in their back could be the first sign of serious injury. ${ }^{36}$ Similar findings have been reported in Australia. ${ }^{37}$

The influence that competing goals had in this study suggests that self-regulatory processes may be implicated in future iterations of the FAM. $^{5}$ Self-regulatory processes refer to the adjustment of emotions and behaviours depending on the appraisal of goal outcome. ${ }^{38}$ Such feedback processes are currently lacking in the FAM and therefore the model does not account for the fact that pain-related fear and fear avoidance may vary depending on context. ${ }^{5} 10$

\section{Clinical implications}

For individuals presenting with CNSLBP and high painrelated fear, it may be important to consider their beliefs underlying fear and provide targeted interventions to help them make sense of their pain.

Where possible, strategies that improve pain controllability, predictability and intensity may be effective in reducing the threat LBP poses to individuals. There is currently debate as to whether pain control should be a target of interventions for CNSLBP. For example, approaches such as acceptance and commitment therapy (ACT) recommend that pain controllability should not be a target of treatment, while approaches such as cognitive functional therapy (CFT) explicitly target pain control, where achievable, as a focus of the intervention. To date, ACT has reported modest effect sizes for disability, but little improvement in pain. ${ }^{39}$ In contrast, a recent randomised control trial reported large effect sizes for pain and disability reduction through CFT. ${ }^{40}$ As symptom attenuation is an important construct of recovery for individuals with CNSLBP, ${ }^{41}$ it would appear unfounded to miss an opportunity to target pain control in the lack of evidence that purely targeting cognitive processes yields superior outcomes. Clearly exploration in this area is warranted.

Individuals presenting with damage beliefs are likely to benefit from an acceptable, individualised, biopsychosocial understanding of CNSLBP using unambiguous language. It is important to question patients with damage beliefs about their past health experiences, including what they have previously been told about their LBP and any scans they have had. The findings highlight a need for further research to better understand how diagnostic jargon commonly used in the LBP context such as 'degeneration' are experienced and interpreted by patients with CNSLBP. Bridging this language gap should be recognised as a LBP research priority to prevent the inadvertent perpetuation of damage beliefs by HCPs.

For all patients presenting with high pain-related fear, asking about any previous negative experiences of LBP can provide insight into how these contribute to expectations of pain and its consequences. Interventions may include strategies that discourage pessimistic expectancies, replacing them with more optimistic attitudes towards the achievement of valued goals. ${ }^{42}$
Individuals presenting with suffering/functional loss beliefs may respond to approaches which link paincontrol strategies to functional goals. This may be achieved via measures that target the regulation of an individuals' emotional responses to pain and activity pacing ${ }^{43}$ while addressing maladaptive functional behaviours (such as muscle guarding) associated with feared or avoided movements. ${ }^{44}$ In some cases combining these strategies with pharmacology may assist the process of dampening pain responses to functional tasks. ${ }^{45}$ Combined with approaches which improve goal setting, goal pursuit and goal flexibility ${ }^{46}$ this may enhance fear reduction in individuals who repeatedly fail to achieve functional goals due to pain.

\section{Strengths and limitations}

The authors make explicit their clinical experience in the area of biopsychosocial CNSLBP management and familiarity with the literature. It is a limitation of this study that only one author performed coding of all transcripts. However, we emphasise the inductive nature of the analytic process and the trustworthy measures employed to ensure that the findings were grounded in the participants' experiences.

Another limitation of this study is that only individuals who contacted the researchers were included. It is possible that this sample differed in important ways to the population from which they came. In this sample we were able to identify a predominant belief underlying fear, with overlap in a minority of cases. It is unknown how representative this finding is to the greater population of individuals with CNSLBP and high pain-related fear.

\section{Future research}

Future research is needed to explore the beliefs underlying pain-related fear and how they evolve in larger and more diverse populations of people with CNSLBP.

Future intervention studies involving participants with CNSLBP and high pain-related fear are needed to explore whether sense-making processes play a role in fear reduction. Such studies will require repeated measures throughout the intervention period to better understand the mechanisms involved in sense-making. Including qualitative interviews in the design of future intervention studies would enhance our understanding of how these mechanisms may differ between individuals.

Future randomised controlled trials are needed to better understand the role that pain controllability plays in pain-related fear and fear reduction. Such studies may compare interventions that target pain controllability such as CFT to interventions such as ACT that target pain acceptance over pain controllability.

\section{CONCLUSION}

The findings of this study suggest that multiple factors may trigger the vicious cycle of pain-related fear. Future iterations of the FAM may draw on these findings to 
consider ascribing a greater role to somatic aspects of the LBP experience on the pathway to pain-related fear. Similarly, future iterations may consider the role that sense-making processes play on the pathways to painrelated fear. Whether, if and how targeting the somatic aspects of the LBP experience and sense-making processes might influence fear reduction remains to be seen.

Contributors All authors were involved in the design of the study. SB conducted the participant recruitment, conducted and transcribed all interviews, performed the coding and led the interpretive process. The coauthors AS, RS and POS read the raw transcripts, independently coded a random sample of eight interviews and were involved in all stages of the data analysis. All authors had input into, and approved, the final manuscript.

Funding SB was funded by an Australian Postgraduate Award and Curtin University Postgraduate Scholarship for doctoral research.

Competing interests None declared.

Ethics approval This study was approved by Curtin University Human Research Ethics Committee and local hospital ethics committees in Perth, Western Australia.

Provenance and peer review Not commissioned; externally peer reviewed.

Data sharing statement Extracts from this data set may be made available by emailing the corresponding author.

Open Access This is an Open Access article distributed in accordance with the Creative Commons Attribution Non Commercial (CC BY-NC 4.0) license, which permits others to distribute, remix, adapt, build upon this work noncommercially, and license their derivative works on different terms, provided the original work is properly cited and the use is non-commercial. See: http:// creativecommons.org/licenses/by-nc/4.0/

\section{REFERENCES}

1. Storheim K, Brox JI, Holm I, et al. Predictors of return to work in patients sick listed for sub-acute low back pain: a 12-month follow-up study. J Rehabil Med 2005;37:365-71.

2. Turner J, Franklin G, Fulton-Kehoe D, et al. Worker recovery expectations and fear-avoidance predict work disability in a population-based workers' compensation back pain sample. Spine 2006;31:682-9.

3. Lazarus $\mathrm{R}$. Thoughts on the relations between emotion and cognition. Am Psychol 1982;37:1019-24.

4. Vlaeyen J, Linton S. Fear-avoidance and its consequences in chronic musculoskeletal pain: a state of the art. Pain 2000;85:317-32.

5. Crombez G, Eccleston C, Van Damme S, et al. Fear avoidance model of chronic pain: the next generation. Clin J Pain 2012;28:475-83.

6. Goubert L, Crombez G, Van Damme S. The role of neuroticism, pain catastrophizing and pain-related fear in vigilance to pain: a structural equations approach. Pain 2004;107:234-41.

7. Wideman $T$, Adams $H$, Sullivan M. A prospective sequential analysis of the fear-avoidance model of pain. Pain 2009;145:45-51.

8. Picavet S, Vlaeyen J, Schouten J. Pain catastrophizing and kinesiophobia: predictors of chronic low back pain. Am J Epidemiol 2002;156:1028-34.

9. Jensen JN, Karpatschof B, Labriola M, et al. Do fear-avoidance beliefs play a role on the association between low back pain and sickness absence? A prospective cohort study among female health care workers. J Occup Environ Med 2010;52:85-90.

10. Vlaeyen JW, Linton SJ. Fear-avoidance model of chronic musculoskeletal pain: 12 years on. Pain 2012;153:1144-7.

11. Pincus $T$, Smeets $R$, Simmonds $M$, et al. The fear avoidance model disentangled: improving the clinical utility of the fear avoidance model. Clin J Pain 2010;26:739-46.

12. Asmundson G, Vlaeyen J, Crombez G. Understanding and treating fear of pain. New York: Oxford University Press, 2004.

13. Leeuw M, Goossens M, van Breukelen G, et al. Exposure in vivo versus operant graded activity in chronic low back pain patients: results of a randomized controlled trial. Pain 2008;138:192-207.
14. Linton $\mathrm{S}$, Boersma $\mathrm{K}$, Jansson $\mathrm{M}$, et al. A randomized controlled tria of exposure in vivo for patients with spinal pain reporting fear of work related activities. Eur J Pain 2008;12:722-30.

15. Woods M, Asmundson G. Evaluating the efficacy of graded in vivo exposure for the treatment of fear in patients with chronic back pain: a randomized controlled clinical trial. Pain 2008;136:271-80.

16. Stenberg G, Fjellman-Wiklund A, Ahlgren C. 'I am afraid to make the damage worse'-fear of engaging in physical activity among patients with neck or back pain-a gender perspective. Scand J Caring Sci 2014;28:146-54.

17. Darlow B, Dowell A, Baxter G, et al. The enduring impact of what clinicians say to people with low back pain. Ann Fam Med 2013;11:527-34.

18. Wertli M, Rasmussen-Barr E, Weiser S, et al. The role of fear avoidance beliefs as a prognostic factor for outcome in patients with nonspecific low back pain: a systematic review. Spine $J$ 2014;14:816-36.

19. Bunzli S, Smith A, Watkins R, et al. What do people who score highly on the Tampa Scale of Kinesiophobia really believe? A mixed methods investigation in people with chronic non-specific low back pain. Clin J Pain 2015;31:621-32.

20. Thorne S, Reimer Kirkham S, MacDonald-Emes J. Interpretive description: a noncategorical qualitative alternative for developing nursing knowledge. Res Nurs Health 1997;20:169-77.

21. Tong A, Sainsbury $P$, Craig J. Consolidated criteria for reporting qualitative research (COREQ): a 32-item checklist for interviews and focus groups. Int J Qual Health Care 2007;19:349-57.

22. Vlaeyen J, de Jong J, Geilen M, et al. The treatment of fear of movement/(re)injury in chronic low back pain: further evidence on the effectiveness of exposure in vivo. Clin J Pain 2002;18:251-61.

23. Thorne S, Reimer Kirkham S, O'Flynn-Magee K. The analytic challenge in interpretive description. Int J Qual Methods 2004;3:1-11.

24. Bunzli S, Watkins $\mathrm{R}$, Smith $\mathrm{A}$, et al. Lives on hold: a qualitative synthesis exploring the experience of chronic low back pain. Clin $J$ Pain 2013;29:907-16.

25. Toye F, Barker K. 'I can't see any reason for stopping doing anything, but I might have to do it differently'-restoring hope to patients with persistent non-specific low back pain-a qualitative study. Disabil Rehabil 2012;34:894-903.

26. Snelgrove S, Edwards S, Liossi C. A longitudinal study of patients' experiences of chronic low back pain using interpretative phenomenological analysis: changes and consistencies. Psychol Health 2013;28:121-38.

27. Lin I, O'Sullivan P, Coffin J, et al. Disabling chronic low back pain as an iatrogenic disorder: a qualitative study in Aboriginal Australians. BMJ Open 2013;3:e002654.

28. Glaser B, Strauss A. The discovery of grounded theory: strategies for qualitative research. Chicago: Aldine, 1967.

29. Lillrank $A$. Back pain and the resolution of diagnostic uncertainty in illness narratives. Soc Sci Med 2003;57:1045-54.

30. Campbell C, Guy A. 'Why can't they do anything for a simple back problem?': a qualitative examination of expectations for low back pain treatment and outcome. J Health Psychol 2007;12: 641-52.

31. van Wilgen $C$, van Ittersum $M$, Kaptein $A$, et al. Illness perceptions in patients with fibromyalgia and their relationship to quality of life and catastrophising. Arthritis Rheum 2008;58:3618-26.

32. Armfield J. Cognitive vulnerability: a model of the etiology of fear Clin Psychol Rev 2006;26:746-68.

33. Meulders A, Vansteenwegen D, Vlaeyen J. The acquisition of fear of movement-related pain and associative learning: a novel pain-relevant human fear conditioning paradigm. Pain 2011:152:2460-9.

34. Crombez G, Eccleston $\mathrm{C}$, De Vlieger $\mathrm{P}$, et al. Is it better to have controlled and lost than never to have controlled at all? An experimental investigation of control over pain. Pain 2008;137:631-9.

35. Crombez G, Viane I, Eccleston C, et al. Attention to pain and fear of pain in patients with chronic pain. J Behav Med 2013;36:371-8.

36. Darlow B, Perry M, Stanley J, et al. Cross-sectional survey of attitudes and beliefs about back pain in New Zealand. BMJ Open 2014;4:e004725.

37. Briggs A, Jordan J, Buchbinder R, et al. Health literacy and beliefs among community cohort with and without chronic low back pain. Pain 2010;150:275-83

38. Leventhal H, Meyer D, Nerenz D. The common sense representation of illness danger. In: Rachman S, ed. Medical psychology. Elmsford, NY: Pergamon, 1980:7-30

39. McCracken L, Gutierrez-Martinez O. Processes of change in psychological flexibility in an interdisciplinary group-based treatment 
for chronic pain based on acceptance and commitment therapy. Behav Res Ther 2011;49:267-74.

40. Vibe Fersum K, O'Sullivan P, Skouen J, et al. Efficacy of classification-based cognitive functional therapy in patients with non-specific chronic low back pain: a randomized controlled trial. Eur J Pain 2013;17:916-28.

41. Hush J, Refshauge K, Sullivan G, et al. Recovery: what does this mean to patients with low back pain? Arthritis Rheum 2009;61:124-31.

42. Affleck G, Tennen H, Zautra A, et al. Women's pursuit of personal goals in daily life with fibromyalgia: a value-expectancy analysis. J Consult Clin Psychol 2001;69:587-96.
43. Hasenbring M, Verbunt J. Fear avoidance and endurance related responses to pain: new models of behaviour and their consequences for clinical practice. Clin J Pain 2010;26: 747-53.

44. O'Sullivan P. Diagnosis and classification of chronic low back pain disorders: maladaptive movement and motor control impairments as underlying mechanism. Man Ther 2005;10:242-55.

45. Woolf CJ, Mannion RJ. Neuropathic pain: aetiology, symptoms, mechanisms, and management. Lancet 1999;353:1959-64.

46. Christiansen S, Oettingen G, Dahme B, et al. A short goal-pursuit intervention to improve physical capacity: a randomized clinical trial in chronic back pain patients. Pain 2010;149:444-52. 